\title{
Modelo Conceitual de Decisões no Estágio de Criação de um Negócio: Base para Construção de um Simulador para Jogos de Empresas
}

\section{Conceptual Model of Decisions in New Venture Creation Stage: Basis for Modeling a Simulator for Business Games}

André Rosenfeld Rosas *

Antonio Carlos Aidar Sauaia 


\section{RESUMO}

O estudo teve como objetivo desenvolver um modelo conceitual para jogo de empresas que reúne as principais decisões de um empreendedor no estágio de criação de um negócio. As decisões, identificadas na literatura de empreendedorismo que foca o processo de criação de negócios, foram modeladas pelo método do diagrama de influências e confirmadas com especialistas norte-americanos e brasileiros no tema. $\mathrm{O}$ modelo conceitual resultante, aqui proposto para a criação de um simulador, foi comparado a dois simuladores acadêmicos identificados na literatura. As contribuições deste estudo foram: elaborar um modelo para simulador de empreendedorismo com coerência conceitual, identificar decisões não presentes ou parcialmente presentes nos demais simuladores e contextualizá-lo ao ambiente brasileiro. O modelo proposto visa estimular a prática de decisões e de conceitos de gestão em cursos de Empreendedorismo. A pesquisa prossegue rumo à modelagem matemática com aplicações-teste.

Palavras-chave: empreendedorismo; decisões; simulador; jogos de empresas.

\section{ABSTRACT}

The aim of this research was to build a conceptual model for business games focusing on the main decisions an entrepreneur faces during the new venture creation stage. The decisions were captured from the literature focused on the process of creating a new business. They were modeled using the influence diagram method and confirmed by American and Brazilian specialists. The resulting conceptual model proposed for building a simulator was compared to two other academic simulators. This research has three contributions: a model for an entrepreneurship simulator with conceptual validity, identification of decisions not present or partially present in academic simulators, and an adjustment of the game for the Brazilian context. The proposed model aims to stimulate the practice of decisions and management concepts in Entrepreneurship courses. This research is being further developed through mathematical modeling and testing in classrooms.

Key words: entrepreneurship; decisions; simulator; business games. 


\section{INTRODUÇÃO}

O empreendedorismo emergiu novamente com destaque no contexto econômico mundial, a partir da década de 70. Foi naquele momento que os mercados europeu e norte-americano começaram a saturar. Tal fato, combinado com a disseminação de produtos japoneses durante a ascensão do Toyotismo, aumentando a oferta, e com as crises do petróleo, momento de estagflação, gerou redução sensível de empregos. Como decorrência, o equilíbrio no mercado de trabalho foi viabilizado pelas pequenas empresas, responsáveis pela maioria dos empregos criados na época (Birch, 1987, p. 16).

No Brasil, a importância do empreendedorismo pode ser observada nos dados levantados pelo Instituto Brasileiro de Geografia e Estatística [IBGE] (Serviço Brasileiro de Apoio às Micro e Pequenas Empresas [SEBRAE], 2005, p. 11): 99\% das empresas formais no setor privado urbano brasileiro são micro e pequenas [MPEs] e geram 57\% do total de empregos. Apesar de MPE não ser sinônimo de empreendedorismo, cabe destacar que a maior parte dos novos negócios se inicia com este porte. Embora expressivas, tais estatísticas estão associadas a um fato digno de nota: a taxa de mortalidade de MPEs com até quatro anos de existência é de 60\% (SEBRAE, 2004, p. 19).

Para definir empreendedorismo neste estudo foi utilizada a classificação do Global Entrepreneurship Monitor [GEM], a qual distingue dois tipos de empreendedores: os que iniciam suas atividades devido a uma oportunidade de negócio daqueles que empreendem em função de uma necessidade de sobrevivência. Como exemplo, Bosma e Harding (2007) assinala que no Brasil 50\% empreende por necessidade, enquanto nos EUA $80 \%$ decide empreender para explorar uma oportunidade de negócios. Como o objetivo deste estudo é apoiar a formação de empreendedores em geral, o empreendedor-alvo aqui tratado é todo aquele que busca empreender perseguindo oportunidades, mesmo que sua motivação primeira seja a necessidade.

Tomando-se por base o empreendedor caçador de oportunidades e a necessidade de redução da taxa de mortalidade dos negócios, definiu-se como objetivo geral do estudo desenvolver um simulador educacional para vivência, pelos alunos, do processo de exploração de oportunidades de negócios. Este artigo, mais especificamente, apresenta um modelo conceitual com as principais decisões a serem praticadas na aprendizagem do processo empreendedor. O foco está no modelo conceitual, não se abordando a modelagem matemática, etapa em elaboração a ser apresentada em publicação futura. Compara-se, ainda, o modelo conceitual com simuladores acadêmicos existentes, destacando-se as contribuições para a literatura. $\mathrm{O}$ modelo proposto foi desenvolvido para o primeiro estágio do Ciclo de Vida das Organizações (Figura 1): o de Criação de um negócio.

Figura 1: Modelo de Ciclo de Vida das Empresas

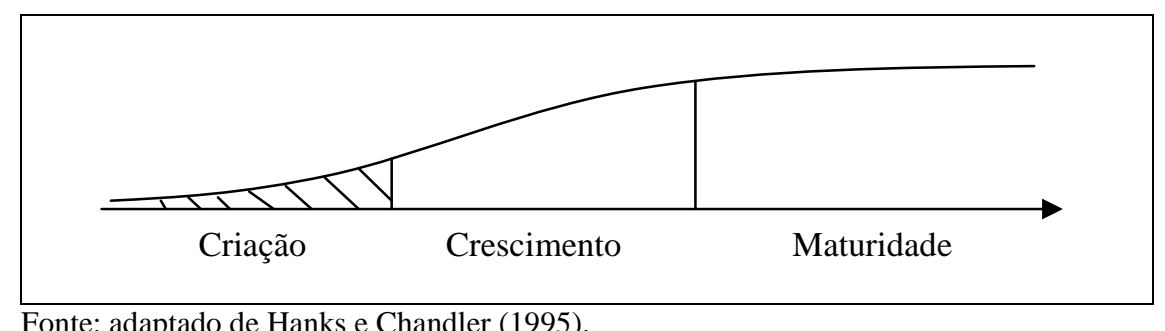




\section{REFERENCIAL TEÓRICO}

\section{Definindo Empreendedorismo}

Dentre os conceitos discutidos na literatura, alguns são recorrentes (Brouwer, 2002; Murphy, Liao, \& Welsch, 2006): em particular os conceitos propostos por Cantillon, Say, Schumpeter, Knight e Kirzner. Para o presente estudo foram adotados os três últimos autores.

De acordo com a abordagem econômica de Schumpeter (1934), o empreendedor é o inovador que cria combinações que trazem descontinuidade - novos produtos, mercados, métodos de produção, fontes de fornecimento ou reorganização da indústria. Este empreendedor era visto como o motor do crescimento econômico de um país.

Para Knight (1921) o empreendedor vive em um mundo de constantes mudanças, lidando com situações de risco e incerteza. Na primeira situação a probabilidade de eventos futuros é conhecida $a$ priori. Já na segunda, a expectativa de eventos futuros é resultado de julgamento ou intuição. $\mathrm{O}$ empreendedor assume riscos em condições de incerteza, buscando antecipar mudanças e produzir novo tipo de atividade que lhe permitirá obter lucros.

Dado o mercado competitivo descrito na Introdução, surgiu na década de 70 a noção de Kirzner (1979): o empreendedor, atuando em mercado competitivo, está alerta para oportunidades de lucro existentes, aproveitando o conhecimento imperfeito do mercado.

Para este estudo, com base nestes conceitos, o empreendedor é tido como aquele que está sempre perseguindo novas oportunidades de negócios, por meio de inovações - novos produtos e mercados gerenciando seus riscos e convivendo com ambiente de incerteza.

\section{Empreendedorismo no Contexto Brasileiro}

As características do empreendedorismo brasileiro identificadas na literatura foram organizadas de acordo com quatro grupos de decisões: 1) posicionamento no mercado; 2) finanças; 3) formação de equipe de trabalho e rede de contatos; e 4) aspectos formais e legais. Esta taxonomia, elaborada neste estudo, advém da disposição dos capítulos em dois livros que focalizam o processo de Criação de Empresas (Holt, 1992; Timmons \& Spinelli, 2006) combinada com a disseminada divisão funcional em Administração, ou seja, as áreas de Marketing, Operações, Finanças e Recursos Humanos.

Decisões quanto ao posicionamento no mercado envolvem as áreas de Estratégia, Marketing \& Vendas, P\&D \& Inovação, Operações e Suprimentos. As características em destaque neste grupo são relativas à função de inovação em produtos. No Brasil a infra-estrutura de Ciência e Tecnologia está principalmente localizada em Universidades financiadas pelo Governo (Lahorgue \& Cunha, 2003, p. 203). O sucesso das iniciativas tecnológicas de empresas emergentes depende dos centros de pesquisa de tais universidades, de modo a viabilizar atualizações tecnológicas de produtos, processos ou serviços (Judice \& Baêta, 2005, p. 184). Outro dado interessante é o número reduzido de pessoas trabalhando em tempo integral em $\mathrm{P} \& \mathrm{D}$, em comparação com países desenvolvidos, evidenciando a menor disponibilidade de recursos para tal fim no contexto nacional (Barbieri, 1999, p. 55).

As características referentes às decisões financeiras foram as mais recorrentes na literatura. $\mathrm{O}$ empreendedorismo brasileiro possui como fonte predominante o capital próprio (SEBRAE, 2004, p. 29). A oferta de capital de risco, ou venture capital, ainda é incipiente e primariamente advém do Governo (Andreassi \& Siqueira, 2005, p. 9; Judice \& Baêta, 2005, p. 186). Fontes de financiamento alternativas, como os bancos, são muitas vezes inviáveis por conta do elevado custo de capital originado pelas altas taxas de juros da economia brasileira, além das exigências de garantias para fornecimento de crédito (Andreassi \& Siqueira, 2005, p. 5). O último ponto comum às micro e pequenas empresas, que talvez seja agravado no contexto brasileiro devido ao menor PIB per capita 
em comparação com países desenvolvidos, é a escassez de capital de giro em face das baixas receitas (Dutra, 2004, p. 10).

Quanto à formação de equipe de trabalho e rede de contatos, dois aspectos merecem atenção. $\mathrm{O}$ primeiro refere-se ao custo elevado dos encargos trabalhistas, dificultando a formalização das relações de trabalho (Araújo et al., 2005, p. 19). O segundo é a expansão da utilização de redes de negócios empresariais, visando redução de custos em comunicação de marketing, em comercialização e nas operações, ou seja, economias de escala, escopo e especialização (Balestrin \& Vargas, 2004, p. 221).

O último grupo de decisões, aspectos formais e legais do negócio, inclui Administração Pública, Direito do Trabalho e Empresarial e Contabilidade. Foram dois os aspectos que se destacaram neste grupo: carga tributária e registros de propriedade intelectual. Silva e Pereira (2004, p. 13) identificaram em 86 empresas os principais fatores de decisão nos estágios de criação e gestão delas. $\mathrm{O}$ fator de maior influência no estágio de criação, foco deste estudo, foi a carga tributária. O outro aspecto refere-se aos baixos índices de registro de propriedade intelectual junto ao Instituto Nacional da Propriedade Industrial [INPI] (Judice \& Baêta, 2005, pp. 184-185) que, em muitos casos, se devem aos altos custos associados (Barbieri, 1999, p. 56).

A Tabela 1 sintetiza as características do empreendedorismo brasileiro que direcionaram o ajuste do modelo conceitual ao contexto nacional.

\section{Tabela 1: Características do Empreendedorismo Brasileiro}

\begin{tabular}{|c|c|}
\hline $\begin{array}{l}\text { Posicionamento no mercado } \\
\text { (P\&D): Judice e Baeta } \\
\text { (2005); Lahorgue e Cunha } \\
\text { (2003); Barbieri (1999). }\end{array}$ & $\begin{array}{l}\text { - Governo é a principal fonte de recursos para pesquisa e desenvolvimento, } \\
\text { porém é pequeno o volume comparado com países desenvolvidos; } \\
\text { - Dependência de Instituições de Ensino e Pesquisa para desenvolver produtos. }\end{array}$ \\
\hline $\begin{array}{l}\text { Finanças: Judice e Baeta } \\
\text { (2005); Andreassi e Siqueira } \\
\text { (2005); SEBRAE (2004); } \\
\text { Dutra (2004). }\end{array}$ & $\begin{array}{l}\text { - Capital próprio é fonte predominante de financiamento; } \\
\text { - Alto custo de capital devido a altas taxas de juros; } \\
\text { - Falta de capital de giro; } \\
\text { - Difícil acesso ao crédito devido à necessidade de garantias; } \\
\text { - Oferta de venture capital incipiente e primariamente advém do Governo. }\end{array}$ \\
\hline $\begin{array}{l}\text { Equipe de trabalho e rede de } \\
\text { contatos: Araújo et al. } \\
\text { (2005); Balestrin e Vargas } \\
(2004) \text {. }\end{array}$ & $\begin{array}{l}\text { - Encargos trabalhistas possuem um custo elevado dificultando relações } \\
\text { formais de emprego; } \\
\text { - Redes de negócios geram economias de custos por meio de marketing } \\
\text { conjunto, economias de escala e escopo, e exportação conjunta. }\end{array}$ \\
\hline $\begin{array}{l}\text { Aspectos formais e legais: } \\
\text { Judice e Baeta (2005); Silva } \\
\text { e Pereira (2004); Barbieri } \\
\text { (1999). }\end{array}$ & $\begin{array}{l}\text { - Alta carga tributária resultando em alta informalidade; } \\
\text { - Altos custos de registro de propriedade intelectual (INPI). }\end{array}$ \\
\hline
\end{tabular}

\section{Panorama Acadêmico da Educação em Empreendedorismo}

Em um panorama acadêmico internacional, o empreendedorismo ganhou impulso a partir da década de 80. Um exemplo é o crescimento de número de universidades norte-americanas com cursos específicos sobre o tema: de seis, em 1967, para 300, em 1988 (Vesper \& Mcmullan, 1988, p. 8). Outro dado que exemplifica este impulso é o aumento de 101 posições eméritas - endowed - em empreendedorismo no mundo em 1991 para 563 em 2003 (Katz, 2003). Apesar de diversos métodos educacionais serem utilizados (Henry, Hill, \& Leitch, 2005, p. 105), o foco permanece na elaboração de planos de negócios, mesmo com sua restrição quanto ao fornecimento de feedback aos participantes, como pode ser observada a ênfase dada a competições de caso, nas principais escolas de administração americanas (Harvard Business School, 2008).

Quanto ao panorama acadêmico brasileiro, o empreendedorismo foi introduzido em Instituições de Ensino Superior [IES] no início da década de 80. As instituições pioneiras foram a EAESP/FGV, USP e UFRGS (Araújo et al., 2005, p. 21). No mesmo período, o tema passou a ser estudado em nível de 
doutorado em Administração (Santos, 1983). Desde sua introdução, estes cursos vêm sendo expandidos na educação superior. Em levantamento recente com 131 IES públicas e privadas identificavam-se 346 docentes atuantes (Souza, Souza, Assis, \& Zerbini, 2004, p. 8). Destaca-se um dado importante para o presente estudo levantado por Souza et al. (2004, p. 9): os jogos e o estudo de casos figuram como as técnicas educacionais menos utilizadas. Este fato confirma a existência de uma oportunidade de desenvolvimento de ferramentas para a formação prática em empreendedorismo.

Esta formação prática pode ser calcada em dois sentidos: desenvolvendo-se um conjunto de habilidades comuns aos empreendedores, ou praticando-se decisões comuns aos empreendedores. A primeira dessas abordagens, advinda dos estudos de Psicologia, ofereceu resultados não conclusivos de pesquisas sobre o perfil do empreendedor (Stevenson, 1999, p. 9). A base do presente estudo está na abordagem educacional de Administração e Economia, que propõe a vivência do processo empreendedor, ou seja, a prática das decisões comuns aos empreendedores (Holt, 1992; Timmons \& Spinelli, 2006).

\section{Jogos de Empresas}

Os primeiros jogos de empresas foram desenvolvidos na década de 50, com a função de fornecer formação para executivos baseada em prática de gestão (Bellman, Clark, Malcolm, Craft, \& Ricciardi, 1957, p. 469). Para Andlinger (1958, p. 115) eles eram vistos como a primeira tentativa promissora de prover experiência a executivos, permitindo-lhes gerir empresas simuladas sem incorrer em prejuízos reais. Os jogos de empresas, além da função educacional, também foram reivindicados como laboratórios de pesquisa (Cohen \& Rehnman, 1961, p. 158), sendo até o presente momento utilizados para tal fim em programas de graduação e pós-graduação (Sauaia, 2007) e em pesquisas de pósdoutoramento no Brasil (Sauaia, 2006).

Como dimensão espacial e histórico-temporal, as primeiras aplicações dos jogos de empresas no Brasil datam da década de 70, na Universidade de São Paulo no curso de Administração da FEA (Tanabe, 1973) e na EAESP/FGV (Goldschmidt, 1977), escolas que juntamente com EPS/UFSC seguem até os dias atuais como as referências brasileiras no tema.

Quanto ao futuro do método, Rosas e Sauaia (2006) realizaram um levantamento com especialistas para identificar expectativas de adoção do método de 2005 até 2010 em cursos de graduação e pósgraduação em Administração. Esperava-se, em média, crescimento de $250 \%$, o que indicava clara oportunidade para desenvolvimento de novos modelos.

Como ilustrado na Figura 2, os jogos de empresas são vivências de gestão na qual os participantes, em grupo, elaboram estratégias e tomam decisões para empresas simuladas. O processamento é apoiado por um simulador, sendo os resultados fontes para revisão de estratégias e tomada de novas decisões pelas empresas (Rosas \& Sauaia, 2006).

Figura 2: A Dinâmica de Funcionamento dos Jogos de Empresas

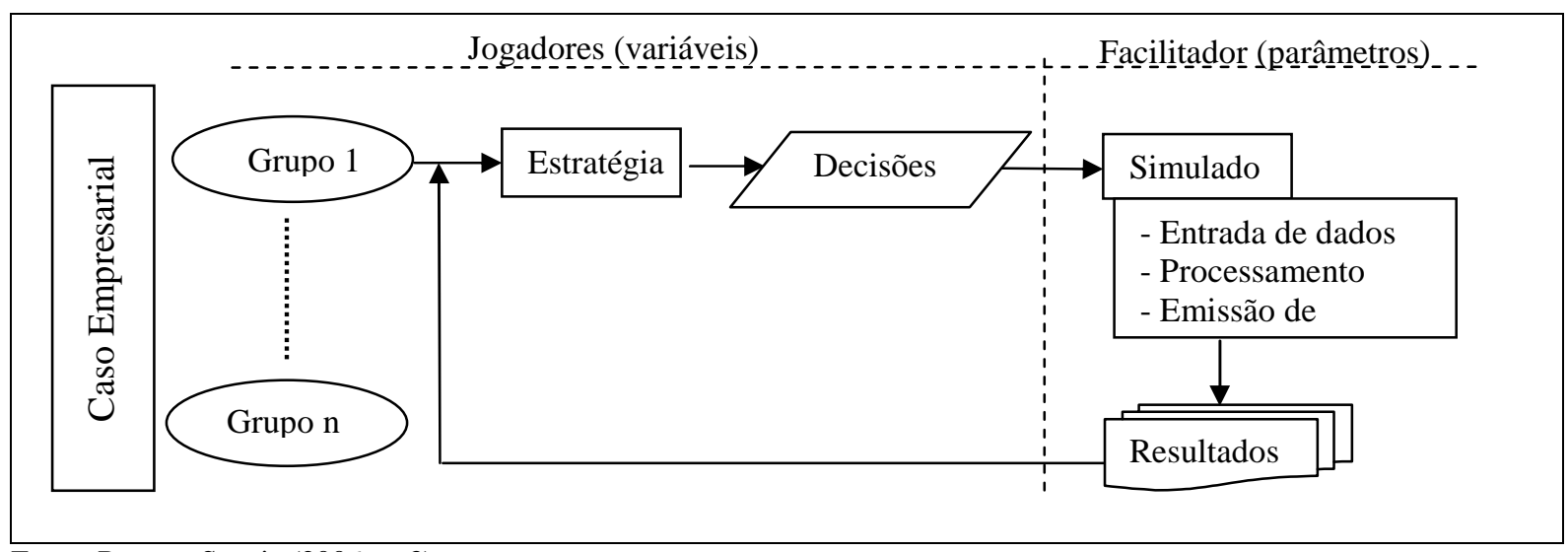

Fonte: Rosas e Sauaia (2006, p. 3). 
Sua principal evolução ao longo do tempo pode ser observada com base em jogos de empresas recentes e de ampla difusão: Capstone (Management Simulation [MSI], 2006) e L'Oréal E-strat (Strategic Excellence [STRATX], 2005). As principais mudanças foram: evolução na tecnologia para aplicação e desenvolvimento, especialmente com advento da internet; incorporação de novos conceitos e teorias no modelo, como a Gestão da Qualidade Total; e modelagem de indústrias recentes, como é o caso dos sensores eletrônicos. A maior parte destes jogos foi elaborada para grandes corporações, empresas centrais no modelo de crescimento econômico vigente no momento em que foram desenvolvidos os primeiros simuladores e que permanece amplamente utilizado.

O presente estudo focaliza o modelo econômico centrado em empreendedorismo (Schumpeter, 1934). Com este enfoque em empreendedorismo somente foram identificados na literatura internacional dois simuladores acadêmicos: Low, Venkataraman e Srivatsan (1994) e Thavikulwat (1995). O primeiro foi aplicado em nível de pós-graduação, e simula a formação de equipe de trabalho e assinatura de contratos com clientes. O segundo foi aplicado em nível de graduação: por um lado inclui a dimensão temporal com tomadas de decisões subseqüentes; contudo a interação usuáriocomputador prejudica a dimensão interpessoal. Discute-se adiante uma comparação destes modelos com o proposto neste estudo.

Por fim, cabe distinguir os jogos sistêmicos dos funcionais (J. B. Keys \& Biggs, 1990, p. 67) para classificar o modelo proposto neste estudo. Enquanto os primeiros tratam a empresa como um organismo integrado, simulando a interação das distintas áreas organizacionais, os segundos são centrados em área funcional, como, por exemplo, marketing. $\mathrm{O}$ modelo proposto neste estudo se enquadra como jogo sistêmico, por incluir decisões das diversas áreas de gestão de um novo negócio.

\section{Procedimento MetodolóGico}

Este estudo pode ser classificado como exploratório, por propor uma intersecção pouco explorada na literatura entre dois temas: jogos de empresas e empreendedorismo. Não se trata somente de um estudo descritivo, porém da proposição de um novo modelo para jogos de empresas, embora ainda na etapa conceitual. A etapa matemática está em desenvolvimento e será tema de publicação futura. Quanto às fontes de dados, trata-se de uma pesquisa bibliográfica complementada por levantamento de campo com professores norte-americanos e brasileiros em empreendedorismo.

O estudo teve início com uma pesquisa bibliográfica nos principais periódicos internacionais sobre Empreendedorismo e em livros que focam o processo de criação de negócios. Como resultado, foram mapeadas quatro decisões-chave para cada um dos quatro grupos de decisões, segundo a taxonomia apresentada acima, no tópico empreendedorismo no contexto brasileiro: posicionamento no mercado; finanças; equipe de trabalho e rede de contatos; e aspectos formais e legais. Esse filtro inicial foi revisado e ampliado por cinco professores em Empreendedorismo da Escola de Administração da Universidade de Vanderbilt (Owen Graduate School, EUA): dois deles são especialistas em um ou dois dos quatro grupos de decisões da taxonomia sugerida neste estudo e três estudam o processo empreendedor de forma sistêmica.

O resultado destas entrevistas foi representado em um diagrama de influências, sendo esta representação a primeira versão do modelo conceitual deste estudo (Clemen \& Reilly, 2001; Shachter, 1986). Este método de modelagem apresenta graficamente as relações entre decisões, incerteza e conseqüências envolvidas em problemas complexos.

Os elementos básicos que compõem um diagrama de influência estão sintetizados na Figura 3. Em resumo, os nós de decisão são precedidos, mediante arcos, de outros nós de decisão ou de incerteza. O resultado das decisões são conseqüências, sendo a última, em especial, definida como nó de objetivo quantificado, pois sinaliza a razão pela qual existe o processo decisório. 
Figura 3: Elementos Básicos do Diagrama de Influência

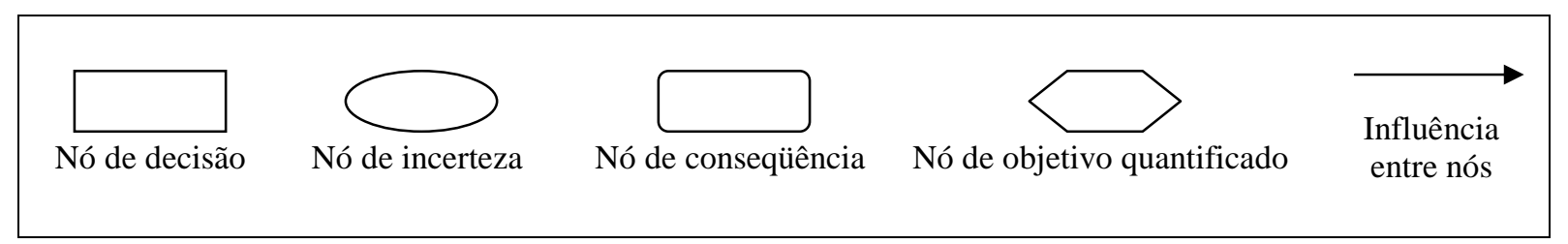

Fonte: Shachter (1986, p. 874) e Clemen e Reilly (2001, p. 52).

Com base na primeira versão do modelo, calcada em referências internacionais, foi realizada uma pesquisa bibliográfica para levantamento das variáveis que permeiam o estágio de criação de um negócio no contexto brasileiro, descritas no tópico empreendedorismo no contexto nacional. Foi obtida do Resultado da Avaliação 2007 (Triênio 2004/2006) dos Programas de Pós-Graduação em Administração, Ciências Contábeis e Turismo pela Coordenação de Aperfeiçoamento de Pessoal de Nível Superior [CAPES], uma listagem de programas de doutorado em Administração e, a partir dela, realizou-se uma busca curricular na Plataforma Lattes (Conselho Nacional de Desenvolvimento Científico e Tecnológico $[\mathrm{CNPq}], 2006)$ visando identificar publicações de professores e pesquisadores destes programas sobre Empreendedorismo. Foram realizadas consultas nos periódicos publicados nos últimos 10 anos e avaliados como nível 'A' nacional pela CAPES. Buscou-se selecionar publicações, cujos títulos continham no mínimo o termo empreende, o que incluiria palavras como empreendedor, empreendedorismo e empreender.

Em um segundo momento, foi realizado um estudo de campo para atualização das variáveis identificadas na literatura nacional. Para tal foram selecionados três professores e pesquisadores em empreendedorismo vinculados a instituições brasileiras de ensino e pesquisa, cujo doutorado em Administração recebeu conceito 6 na avaliação da CAPES: dois da FEA/USP/SP e um da EAESP/FGV. As entrevistas, cuja duração variou de uma hora a uma hora e trinta minutos, buscaram refinar as variáveis - decisões, incertezas e conseqüências - da primeira versão do modelo conceitual, ajustando-o ao contexto brasileiro. Mais adiante (Tabela 2) são apresentadas cada uma destas variáveis, além do julgamento dos professores e pesquisadores brasileiros quanto à sua relevância para o contexto nacional.

Por fim, foi realizada uma análise comparativa do modelo conceitual do simulador proposto com os dois simuladores de empreendedorismo publicados em meios acadêmicos: The Entrepreneurship Game [TEG] (Low et al., 1994) e DEAL (Thavikulwat, 1995). Tais jogos foram identificados na literatura internacional, a partir da busca nos principais periódicos internacionais de empreendedorismo (Katz \& Boal, 2006), no Simulation \& Gaming entre 1990 e 2008, um periódico que focaliza metodologias educacionais práticas, e nos 34 anais da Association for Business Simulation and Experiential Learning [ABSEL] publicados entre 1975 e 2008.

\section{ANÁLISES dOS RESULTADOS E DISCUSSÃo}

\section{Modelo Conceitual: Seleção e Modelagem das Decisões, Incertezas e Conseqüências}

A construção do modelo conceitual partiu da classificação das principais variáveis presentes no contexto empreendedor em decisões, incerteza e conseqüências, de acordo com o método de diagrama de influência. Na Tabela 2 pode-se observar que estas variáveis presentes $(\mathrm{P})$ em dois momentos: Antes - 'A', advindas do levantamento bibliográfico e das entrevistas internacionais - e Depois - 'D', após revisão de professores brasileiros no tema visando à adequação do modelo ao contexto nacional. As decisões estão identificadas de acordo com um dos quatro grupos da taxonomia proposta, conforme legenda do quadro. 
Tabela 2: Decisões, Incertezas e Conseqüências do Modelo Conceitual

\begin{tabular}{|c|c|c|c|c|c|}
\hline $\mathbf{G}$ & Cód. & Descrição & Alternativas & $\mathbf{A}$ & D \\
\hline M & D01 & Qual oportunidade de negócios perseguir? & $\begin{array}{l}\text { Quatro oportunidades na matriz Produto x } \\
\text { Mercado de acordo com o metamodelo. }\end{array}$ & $\mathrm{P}$ & $\mathrm{P}$ \\
\hline $\mathrm{M}$ & D02 & $\begin{array}{l}\text { Que margem de contribuição utilizar no } \\
\text { produto/serviço e nas peças de } \\
\text { reposição/manutenção? }\end{array}$ & $\begin{array}{l}\text { Margens sobre os custos variáveis de } \\
\text { produção. }\end{array}$ & $\mathrm{P}$ & $\mathrm{P}$ \\
\hline $\mathrm{M}$ & D03 & $\begin{array}{l}\text { Quanto investir em P\&D para cada um dos } \\
\text { atributos do produto/serviço? }\end{array}$ & Atributos/pesos definidos pelo facilitador. & $\mathrm{P}$ & $\mathrm{P}$ \\
\hline $\mathrm{M}$ & D04 & $\begin{array}{l}\text { Quanto investir em marketing do produto por } \\
\text { canal de comunicação? }\end{array}$ & $\begin{array}{l}\text { Boca-a-boca, influenciadores/relações } \\
\text { públicas, internet, propaganda. }\end{array}$ & $\mathrm{P}$ & $\mathrm{P}$ \\
\hline $\mathrm{M}$ & $\mathrm{D} 05^{\mathrm{b}}$ & Que canais de venda utilizar? & $\begin{array}{l}\text { Venda direta (para consumidor final ou } \\
\text { para outros negócios) e venda indireta (via } \\
\text { terceiros). }\end{array}$ & $\mathrm{P}$ & $P$ \\
\hline $\mathrm{M}$ & D06 & $\begin{array}{l}\text { Quanto de matéria-prima e equipamentos será } \\
\text { comprado, e de que fornecedor? }\end{array}$ & $\begin{array}{l}\text { Quantidades de matéria-prima e } \\
\text { equipamento disponíveis no mercado. }\end{array}$ & $\mathrm{P}$ & $\mathrm{P}$ \\
\hline $\mathrm{M}$ & D07 & $\begin{array}{l}\text { Quanto produzir e quanto terceirizar (make or } \\
\text { buy)? }\end{array}$ & $\begin{array}{l}\text { Quantidades de produção própria e de } \\
\text { terceiros. }\end{array}$ & $\mathrm{P}$ & $P$ \\
\hline $\mathrm{M}$ & D08 ${ }^{b}$ & $\begin{array}{l}\text { Realizar P\&D interno na empresa e/ou realizar } \\
\text { parceria com instituição de ensino e pesquisa? }\end{array}$ & $\begin{array}{l}\text { Centro interno de pesquisa ou centros } \\
\text { externos de pesquisa de diferentes IES } \\
\text { (negociação com Agência de Inovação da } \\
\text { IES sobre remuneração). }\end{array}$ & $\mathrm{P}$ & $\mathrm{P}$ \\
\hline $\mathrm{F}$ & D09 & $\begin{array}{l}\text { Quais as receitas e despesas mensais estimadas e } \\
\text { em quantos meses a empresa deverá alcançar o } \\
\text { Ponto de Equilíbrio Operacional? }\end{array}$ & $\begin{array}{l}\text { De acordo com 1) o tempo esperado para } \\
\text { alcançar o Ponto de Equilíbrio Operacional } \\
\text { e 2) o grau de aversão a risco, rever D01. }\end{array}$ & $\mathrm{P}$ & $\mathrm{P}$ \\
\hline $\mathrm{F}$ & $\mathrm{D} 10^{\mathrm{b}}$ & $\begin{array}{l}\text { Quanto de financiamento é necessário de cada } \\
\text { fonte? }\end{array}$ & $\begin{array}{l}\text { Recursos próprios (família), parceiros de } \\
\text { negócios, investidores externos, } \\
\text { empréstimo sem garantia do governo } \\
\text { (P\&D), instituições de fomento do } \\
\text { governo, bancos. }\end{array}$ & $\mathrm{P}$ & $\mathrm{P}$ \\
\hline $\mathrm{F}$ & D11 & $\begin{array}{l}\text { Como dividir a participação acionária da } \\
\text { empresa? }\end{array}$ & $\begin{array}{l}\text { Percentual para empreendedor e } \\
\text { colaboradores/sócios. }\end{array}$ & $\mathrm{P}$ & $\mathrm{P}$ \\
\hline $\mathrm{F}$ & D12 & $\begin{array}{l}\text { De que forma é possível se desfazer do negócio } \\
\text { em } 5 \text { anos? }\end{array}$ & $\begin{array}{l}\text { Venda direta, Fusão ou Fechamento com } \\
\text { venda de ativos. }\end{array}$ & $\mathrm{P}$ & $\mathrm{P}$ \\
\hline $\mathrm{E}$ & D13 & $\begin{array}{l}\text { Quem pode transformar a idéia em um produto } \\
\text { real? }\end{array}$ & $\begin{array}{l}\text { Profissionais de ciência e tecnologia (por } \\
\text { meio de acordo societário - propriedade } \\
\text { intelectual). O sócio trabalharia em } \\
\text { instalações próprias ou de terceiros. }\end{array}$ & $\mathrm{P}$ & $\mathrm{P}$ \\
\hline $\mathrm{E}$ & D14 & $\begin{array}{l}\text { Quem irá persuadir o consumidor a comprar o } \\
\text { novo produto e/ou serviço? }\end{array}$ & $\begin{array}{l}\text { Agentes de marketing (por meio de acordo } \\
\text { societário). }\end{array}$ & $\mathrm{P}$ & $P$ \\
\hline $\mathrm{E}$ & D15 & Quem ajudará o empreendedor a produzi-los? & Funcionários operacionais. & $\mathrm{P}$ & $\mathrm{P}$ \\
\hline $\mathrm{E}$ & D16 & Quem venderá o produto e/ou serviço? & Agentes de vendas. & $\mathrm{P}$ & $\mathrm{P}$ \\
\hline
\end{tabular}


Tabela 2 (continuação): Decisões, Incertezas e Conseqüências do Modelo Conceitual

\begin{tabular}{|c|c|c|c|c|c|}
\hline $\mathbf{G}$ & Cód. & Descrição & Alternativas & A & D \\
\hline $\mathrm{E}$ & $\mathrm{D} 17^{\mathrm{b}}$ & $\begin{array}{l}\text { Qual o pacote de compensação oferecido aos } \\
\text { colaboradores? }\end{array}$ & Salário e bônus. & $\mathrm{P}$ & $\mathrm{P}$ \\
\hline $\mathrm{L}$ & $\mathrm{D} 18^{\mathrm{b}}$ & Em que tipo de sociedade empresarial operar? & $\begin{array}{l}\text { Sociedade em comandita simples, } \\
\text { sociedade limitada, e sociedade anônima. }\end{array}$ & $\mathrm{P}$ & - \\
\hline $\mathrm{L}$ & D19 & Qual propriedade intelectual registrar? & $\begin{array}{l}\text { Marca registrada, direitos autorais e } \\
\text { patente. }\end{array}$ & $\mathrm{P}$ & $\mathrm{P}$ \\
\hline M & D20 & $\begin{array}{l}\text { Qual é o próximo produto a ser lançado após o } \\
\text { estágio de criação de empresa? }\end{array}$ & $\begin{array}{l}\text { Depende da criatividade do participante } \\
\text { (em uma avaliação individual) ou do } \\
\text { investimento em P\&D (caso seja um } \\
\text { evento aleatório no jogo). }\end{array}$ & - & $\mathrm{P}$ \\
\hline & I01 & \multicolumn{2}{|l|}{ Tamanho do Mercado } & $\mathrm{P}$ & - \\
\hline & $\mathrm{I} 02$ & \multicolumn{2}{|l|}{ Taxa de crescimento do mercado } & $\mathrm{P}$ & $\mathrm{P}$ \\
\hline & I03 & \multicolumn{2}{|l|}{ Margens do mercado (preço reduzido dos custos) } & $\mathrm{P}$ & $\mathrm{P}$ \\
\hline & $\mathrm{I} 04^{\mathrm{b}}$ & \multicolumn{2}{|l|}{ Taxa de juros definida pelo Banco Central } & $\mathrm{P}$ & $\mathrm{P}$ \\
\hline & $\mathrm{I} 05^{\mathrm{b}}$ & \multicolumn{2}{|l|}{ Taxa cambial } & $\mathrm{P}$ & - \\
\hline & I06 & \multicolumn{2}{|c|}{$\begin{array}{l}\text { Avaliação dos clientes potenciais sobre ações de responsabilidade social e ambiental da } \\
\text { empresa }\end{array}$} & $\mathrm{P}$ & $\mathrm{P}$ \\
\hline & $\mathrm{I} 07$ & \multicolumn{2}{|c|}{ Preferência dos clientes-alvo (atendimento da necessidade do ambiente) } & $\mathrm{P}$ & $\mathrm{P}$ \\
\hline & I08 & \multicolumn{2}{|c|}{ Decisões dos concorrentes que dominam o mercado (reação competitiva) } & $\mathrm{P}$ & $\mathrm{P}$ \\
\hline & I09 & \multicolumn{2}{|l|}{ Atratividade da empresa para investidores } & $\mathrm{P}$ & - \\
\hline & I10 & \multicolumn{2}{|l|}{ Atratividade da empresa para colaboradores } & $\mathrm{P}$ & $\mathrm{P}$ \\
\hline & I11 & \multicolumn{2}{|l|}{ Produtividade dos funcionários de operações } & $\mathrm{P}$ & $\mathrm{P}$ \\
\hline & $\mathrm{I} 12$ & \multicolumn{2}{|l|}{ Demanda por produtos/serviços da empresa } & $\mathrm{P}$ & $\mathrm{P}$ \\
\hline & I13 & \multicolumn{2}{|l|}{ Oferta de produtos/serviços da empresa } & $\mathrm{P}$ & $\mathrm{P}$ \\
\hline & I14 & \multicolumn{2}{|l|}{ Custo variável de produção } & - & $\mathrm{P}$ \\
\hline & I15 & \multicolumn{2}{|c|}{ Relacionamento/interação com cliente (antes e após a venda) } & - & $\mathrm{P}$ \\
\hline & I16 & \multicolumn{2}{|c|}{$\begin{array}{l}\text { Fatores imponderáveis que podem ocorrer durante a simulação (não representado no modelo, } \\
\text { visto que poderá influenciar todas as decisões) }\end{array}$} & - & $\mathrm{P}$ \\
\hline & $\mathrm{C} 01$ & \multicolumn{2}{|l|}{ Receitas e entradas de caixa } & $\mathrm{P}$ & $\mathrm{P}$ \\
\hline & $\mathrm{C} 02$ & \multicolumn{2}{|l|}{ Despesas e saídas de caixa } & $\mathrm{P}$ & $\mathrm{P}$ \\
\hline & OFQ & \multicolumn{2}{|l|}{ Margem de contribuição e liquidez } & $\mathrm{P}$ & $\mathrm{P}$ \\
\hline
\end{tabular}

Legenda: OFQ - objetivo fundamental quantificado; D - decisão; I - incerteza; C - consequiência; b - variáveis que distinguem o empreendedorismo brasileiro; $\mathrm{G}$ - grupo de decisão; M - Posicionamento no mercado; F - Finanças; E Equipe de Trabalho e Rede de Contatos; L - Aspectos formais e legais; A - variáveis antes das entrevistas; D - variáveis depois das entrevistas; P - Presente; '-' - Ausente.

As entrevistas, apoiadas pela revisão da literatura brasileira, definiram as variáveis mais bem ajustadas ao contexto nacional, sendo estas as principais alterações:

- Restrição na decisão de financiamento (D10): ocorre devido à baixa oferta de capitalistas de risco investindo em empresas, pois eles privilegiam papéis do governo com altas taxas de juros (I04). Por esta razão a incerteza quanto à atratividade da empresa para investidores (D09) foi excluída do modelo. 
. Responsabilidade por P\&D (D08): definida com base no risco associado. Como no Brasil o Governo se destaca como a principal fonte de financiamento por meio de instituições públicas de ensino e pesquisa, a empresa pode escolher terceirizar parte ou toda a atividade.

- Menor dúvida quanto ao tipo de sociedade empresarial (D18): uma vez que no contexto brasileiro a tendência é abrir sociedades limitadas, esta decisão foi excluída do modelo. Em mercado no qual é comum a venda de empresas, como no norte-americano, justifica-se a escolha entre tipos de sociedade devido a impostos e custos associados.

- Baixa probabilidade de exportação (I05): como nas entrevistas a probabilidade de novos negócios iniciarem com sua principal receita proveniente de exportação, a incerteza quanto à taxa cambial foi retirada do modelo. Apesar de não citado pelos entrevistados, outro fator para baixa importância da taxa cambial é a baixa volatilidade em voga no Brasil.

As relações entre as variáveis selecionadas foram representadas graficamente pelo método de diagrama de influências. No modelo conceitual (Figura 4) as decisões foram agrupadas de acordo com a taxonomia elaborada neste estudo - posicionamento no mercado, finanças, equipe de trabalho e rede de contatos, e aspectos formais e legais.

O processo decisório tem seu início na identificação e seleção da oportunidade de negócio (Figura 4) que o empreendedor pretende perseguir. As oportunidades podem ser classificadas de acordo com a matriz produto $v s$ mercado, que relaciona a maior inovação do produto e/ou do mercado com maiores riscos (Crawford \& Benedetto, 2003), conforme Figura 5. A escolha por oportunidades de maior risco advém da expectativa de maiores retornos a ele associados (Damodaran, 2003).

\section{Figura 4: Modelo Conceitual do Simulador}

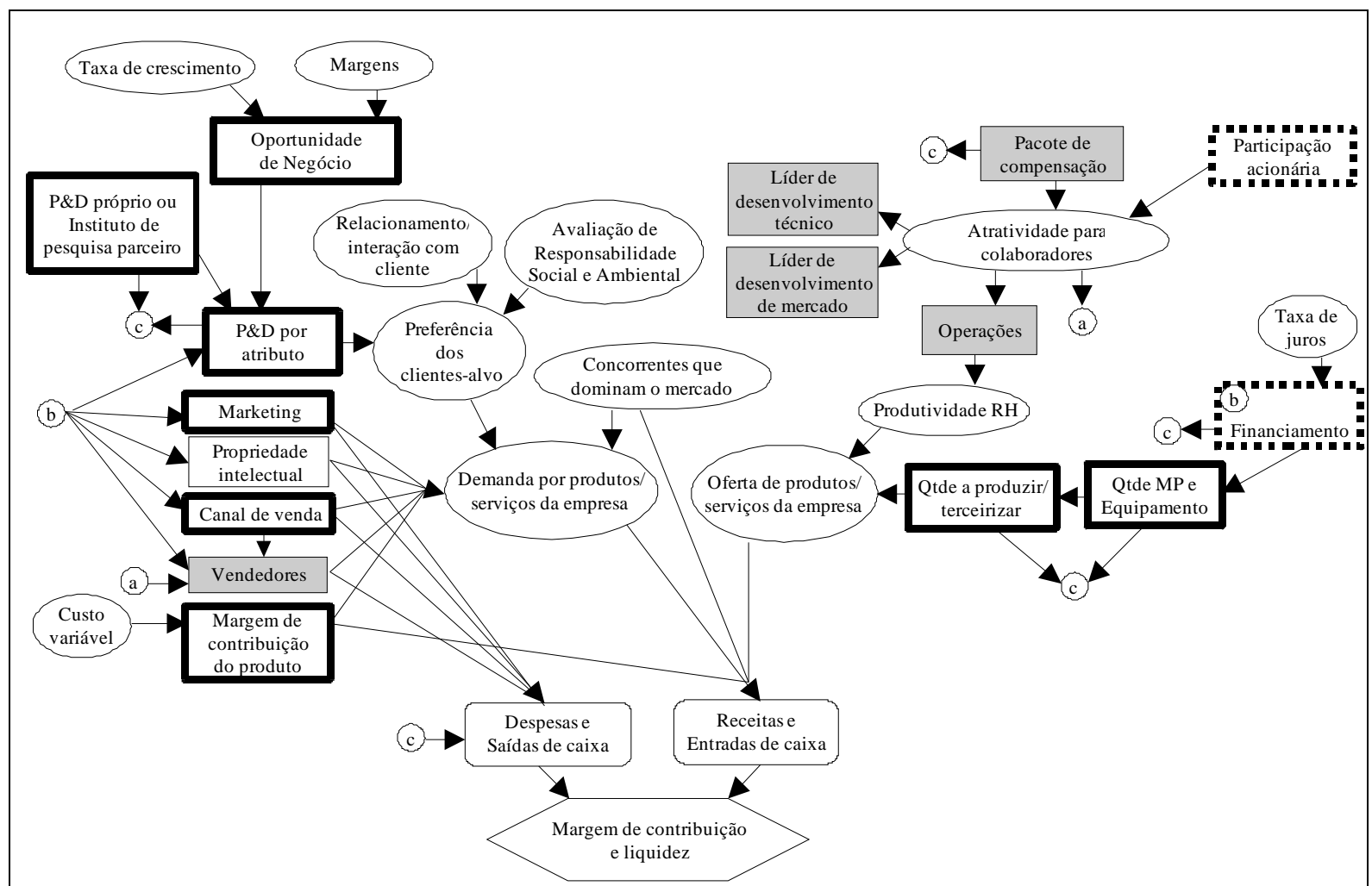

Legenda: Os conectores 'a', 'b' e 'c' substituem arcos visando não poluir visualmente o modelo. Nós de decisão: Fundo branco com borda em negrito - posicionamento no mercado, Bordas tracejadas em negrito - finanças, Fundo cinza claro equipe de trabalho e rede de contatos, Fundo branco - aspectos formais e legais.

Fonte: elaborada pelos autores. 
A decisão da oportunidade a perseguir inicia o processo de criação de um negócio. Os principais critérios para sua decisão são a taxa de crescimento do nicho de mercado focalizado e as margens com as quais espera trabalhar.

\section{Figura 5: Oportunidades de Negócio na Matriz Produto vs Mercado}

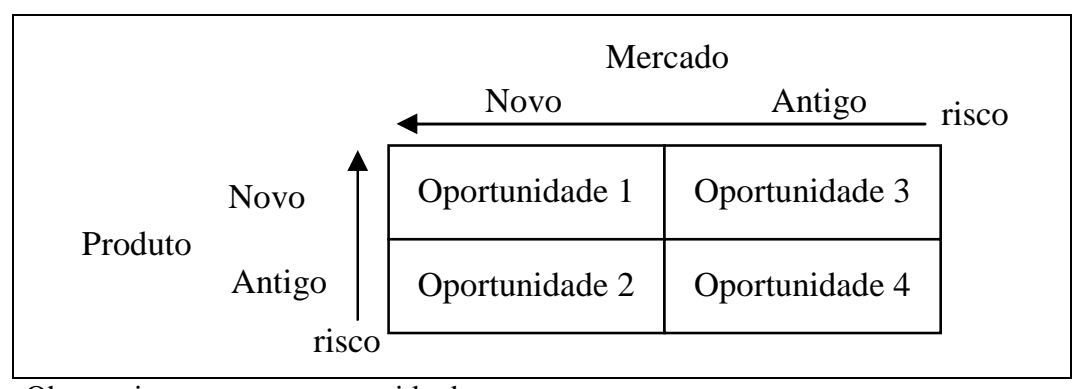

Obs.: o risco aumenta no sentido das setas.

Fonte: adaptado de Crawford e Benedetto (2003, p. 52).

Todas as decisões no primeiro estágio de criação de um negócio convergem para o objetivo de incrementar a margem de contribuição do produto, sem perder o giro suficiente, para que seja alcançado o ponto de equilíbrio operacional e mantida a liquidez no negócio, visto o risco de empréstimos bancários devido às altas taxas de juros.

As decisões de posicionamento no mercado que compreendem as atividades de Marketing, Vendas e $\mathrm{P} \& \mathrm{D}$ influenciam a Demanda por produtos da empresa. $\mathrm{O}$ produto deve estar ajustado às preferências dos clientes-alvo, sua divulgação e seus canais de venda devem atingir tal público e, ainda, seu preço deve ser acessível. Caso a entrada do negócio seja bem sucedida, o investimento em proteção intelectual pode ser realizado, visando garantir demanda de longo prazo. Por outro lado, a demanda pode ser reduzida mediante reação de grandes concorrentes, quer seja por lançarem novos produtos ou então produtos substitutos.

O lado da Oferta compreende as decisões de Gestão de Pessoas, Operações e Finanças. Para apoiar o novo negócio o empreendedor deve buscar pessoas-chave para sua equipe de trabalho, utilizando, entre outros meios, sua rede de contatos para encontrá-las. A atração destas pessoas geralmente ocorre por meio de expectativas de compensações financeiras futuras, quer seja por meio de bônus prometidos ou participação acionária oferecida. O empreendedor ainda deve ser capaz de angariar suficiente capital para a compra de matéria-prima e equipamentos e para cobrir custos fixos nos primeiros meses de operação.

Duas variáveis não explícitas no modelo também devem ser mencionadas: usuários-líderes e parceiros de negócios. Os primeiros estão envolvidos na atividade de $\mathrm{P} \& \mathrm{D}$ e teste de mercado para ajustar as características do produto ou serviço esperadas por usuários com influência sob o públicoalvo (I07). Os parceiros de negócio, por sua vez, permeiam todas as decisões e apóiam, ao oferecerem serviços ou produtos complementares ou ao fornecerem recursos sem requerer pronto ressarcimento.

\section{Contraposição aos Modelos Existentes}

Os simuladores de jogos de empresas para empreendedores identificados na literatura - TEG e DEAL - foram analisados em comparação com as decisões identificadas neste estudo, conforme Tabela 3.

No TEG (Low et al., 1994, pp. 387-388) os estudantes são alocados para diferentes papéis, além do empreendedor: engenheiro, mercadólogo, fornecedor, investidor e consumidor. O sucesso de cada participante depende do sucesso do empreendedor, isto é, o alcance do ponto de equilíbrio 
operacional. O aspecto interpessoal é característico deste modelo. Há necessidade de intensa negociação entre todos participantes.

O DEAL (Thavikulwat, 1995, pp. 334-335) também oferece diversos papéis vivenciados ao mesmo tempo: consumidor, fundador, investidor, diretor, gerente, agente de compra e agente de vendas. As empresas fundadas são financiadas com herança pessoal, com salários recebidos ao atuar como gerente, agente de compra e agente de venda, com dividendos recebidos como investidores e com ganhos de capital na negociação de ações. Este simulador adiciona a dimensão temporal, mediante feedback provido aos participantes, o que possibilita tomada de decisões de modo subseqüente. Por outro lado, o DEAL não oferece a dimensão interpessoal, pois as relações ocorrem por meio de rede de computadores.

Além das diferenças nas decisões presentes no modelo proposto e nos identificados na literatura, conforme Tabela 3, há alguns fundamentos únicos do modelo proposto que merecem destaque:

1) Somente o presente simulador reconhece o Ciclo de Vida das Organizações [CVO] (Hanks \& Chandler, 1995) como base do modelo. Pelo CVO, as decisões prioritárias variam de acordo com o estágio evolutivo em que a empresa se encontra.

2) Diferentemente dos demais modelos, o aqui proposto declara o procedimento metodológico para seleção das decisões a serem praticadas pelos participantes da simulação.

3) Há uma intenção deliberada em integrar o aspecto interpessoal, visto que os participantes deverão atuar pelo menos em duplas - líder de desenvolvimento técnico e líder de desenvolvimento de mercado, com a dimensão temporal, pois as decisões tomadas são subseqüentes, isto é, geram resultados para análise e preparação de novas decisões.

4) No modelo proposto é apresentado o objetivo de gestão que os alunos devem perseguir na criação do negócio. Somente o The Entrepreneurship Game [TEG] define uma meta primária para a empresa: alcançar o ponto de equilíbrio operacional. Esta métrica foi refinada neste estudo, por meio das entrevistas, para margem de contribuição do produto e liquidez.

5) Inclui-se a propensão a riscos técnicos e de mercado na seleção de oportunidades de negócio ilustrados com a matriz produto $v s$ mercado na Figura 5 (Crawford \& Benedetto, 2003, p. 52).

Quanto às diferenças nas decisões simuladas, das 19 decisões presentes no modelo proposto, oito não foram contempladas nos demais modelos e quatro foram tratadas de modo parcial (Tabela 3). Dentre as decisões únicas deste modelo proposto, se destacam as relacionadas ao desenvolvimento do produto ou serviço (D03 e D08), quantidade a ser produzida e terceirização (D07), divulgação (D04) e vendas (D05). Apesar de recorrentes na literatura de Administração, estas foram omitidas no TEG e no DEAL. Este modelo proposto ainda sugere decisões menos recorrentes na literatura, porém identificadas nesta pesquisa como relevantes em empreendedorismo: investimento em proteção intelectual (D19), previsão de lançamento de novos produtos (D20) e planejamento da saída do negócio (D12).

Foram quatro decisões parcialmente cobertas nos demais modelos. A primeira está relacionada ao preço do produto (D02): nenhuma menciona a venda de peças de reposição/manutenção, elemento crítico ao projetar receitas recorrentes para a empresa. Duas outras decisões (D13 e D14) estão limitadas à escolha dos papéis; contudo estes não são vivenciados pelos participantes em decisões subsequientes. A última decisão parcialmente abordada ocorreu no DEAL, no qual está prevista participação acionária (D11) somente a investidores, excluindo-se as demais pessoas-chave. 
Tabela 3: Comparação dos Modelos

\begin{tabular}{|c|c|c|c|c|}
\hline Cód. & Descrição & TEG & DEAL & Proposto \\
\hline D01 & Qual oportunidade de negócios perseguir? & -- & $\mathrm{P}$ & $\mathrm{P}$ \\
\hline D02 & $\begin{array}{l}\text { Que margem de contribuição utilizar no produto/serviço e nas peças de } \\
\text { reposição/manutenção? }\end{array}$ & $\mathrm{P}^{*}$ & $\mathrm{P}^{*}$ & $\mathrm{P}$ \\
\hline D03 & Quanto investir em P\&D para cada um dos atributos do produto/serviço? & -- & -- & $\mathrm{P}$ \\
\hline D04 & Quanto investir em marketing do produto por canal de comunicação? & -- & -- & $\mathrm{P}$ \\
\hline D05 & Que canais de venda utilizar? & -- & -- & $\mathrm{P}$ \\
\hline D06 & $\begin{array}{l}\text { Quanto de matéria-prima e equipamentos será comprado, e de que } \\
\text { fornecedor? }\end{array}$ & $\mathrm{P}$ & $\mathrm{P}$ & $\mathrm{P}$ \\
\hline D07 & Quanto produzir e quanto terceirizar (make or buy)? & -- & -- & $\mathrm{P}$ \\
\hline D08 & $\begin{array}{l}\text { Realizar P\&D interno na empresa e/ou realizar parceria com instituição de } \\
\text { ensino e pesquisa? }\end{array}$ & -- & -- & $\mathrm{P}$ \\
\hline D09 & $\begin{array}{l}\text { Quais as receitas e despesas mensais estimadas e em quantos meses a } \\
\text { empresa deverá alcançar o Ponto de Equilíbrio Operacional? }\end{array}$ & $\mathrm{P}$ & $\mathrm{P}$ & $\mathrm{P}$ \\
\hline D10 & Quanto de financiamento é necessário de cada fonte? & $\mathrm{P}$ & $\mathrm{P}$ & $\mathrm{P}$ \\
\hline D11 & Como dividir a participação acionária da empresa? & $\mathrm{P}$ & $\mathrm{P}^{*}$ & $\mathrm{P}$ \\
\hline D12 & De que forma é possível se desfazer do negócio em 5 anos? & -- & -- & $\mathrm{P}$ \\
\hline D13 & Quem pode transformar a idéia em um produto real? & $\mathrm{P}^{*}$ & -- & $\mathrm{P}$ \\
\hline D14 & Quem irá persuadir o consumidor a comprar o novo produto e/ou serviço? & $\mathrm{P}^{*}$ & -- & $\mathrm{P}$ \\
\hline D15 & Quem ajudará o empreendedor a produzi-los? & $\mathrm{P}$ & -- & $\mathrm{P}$ \\
\hline D16 & Quem venderá o produto e/ou serviço? & - & $\mathrm{P}$ & $\mathrm{P}$ \\
\hline D17 & Qual o pacote de compensação oferecido aos colaboradores? & $\mathrm{P}$ & $\mathrm{P}$ & $\mathrm{P}$ \\
\hline D19 & Qual propriedade intelectual registrar? & -- & -- & $\mathrm{P}$ \\
\hline D20 & $\begin{array}{l}\text { Qual é o próximo produto a ser lançado após o estágio de criação de } \\
\text { empresa? }\end{array}$ & -- & -- & $\mathrm{P}$ \\
\hline$\ldots$ & $\ldots$ & $\ldots$ & $\ldots$ & $\ldots$ \\
\hline D18 & Em que tipo de sociedade empresarial operar? & -- & -- & -- \\
\hline- & Quem comprará os insumos? & -- & $\mathrm{P}$ & -- \\
\hline- & Quanto comprar de cada produto atuando no papel de consumidor final? & -- & $\mathrm{P}$ & -- \\
\hline- & Quanto de dividendo distribuir? & -- & $\mathrm{P}$ & -- \\
\hline- & Presença de investidores privados de risco na decisão de financiamento. & $\mathrm{P}$ & $\mathrm{P}$ & -- \\
\hline
\end{tabular}

Legenda: D - decisão; 'P' - Presente; 'P*' - Parcialmente presente; '--' - Ausente.

Fonte: elaborada pelos autores.

O presente estudo identificou decisões relevantes inexistentes nos modelos revisados. Esses também apresentam decisões aqui não inseridas, sendo descritas em seguida as justificativas para as ausências. Como no Brasil há baixa presença de capital de risco, tal alternativa foi excluída da decisão de financiamento (D10). No DEAL há ainda três aspectos a saber. Não se inseriu a decisão de quem comprará os insumos de produção, pois um papel específico para comprador não foi identificado nas entrevistas internacionais como pessoa-chave. No modelo proposto o aluno tampouco deve vivenciar o 
papel de consumidor, pois este tomará decisões sob a ótica do empreendedor. Por fim, os dividendos não foram aqui modelados, porque, de acordo com o ciclo de vida das organizações (Hanks \& Chandler, 1995), a empresa não possui, no estágio de criação, capital para tal distribuição.

Além das comparações acima discutidas, cabe ressaltar quatro aspectos que tornam o modelo proposto mais bem ajustado ao contexto nacional:

1) Decisão de oportunidade de negócio a perseguir: as indústrias que sobressaem na economia são distintas entre os países. Consequentemente, as oportunidades de negócios modeladas no caso empresarial do simulador devem variar. Outra questão refere-se à exclusão da incerteza 'Tamanho do Mercado' (I01). Tal incerteza é mais presente no contexto norte-americano, visto que é utilizada para o cálculo do valor do negócio e posterior negociação com capitalistas de risco.

2) Decisão de financiamento: pode ser tomada com base no conceito de minimização de recursos ou bootstrapping (Bhidé, 1999, p. 224), válida para ambos os países, ou com base no big money, uma injeção de alta quantia advinda de capitalistas de risco, mais comum no modelo norte-americano (Timmons \& Spinelli, 2006, p. 203). A taxa de juros para ambas as economias é bastante distinta, sendo que as altas taxas praticadas no território nacional (Andreassi \& Siqueira, 2005, p. 5) não estimulam que tais capitalistas invistam em empresas, pois estas teriam que alcançar taxas de retorno muito altas para remunerar o principal. Esta é uma das razões que explicam uma característica marcante no Brasil: o Governo atuando como principal investidor de risco, especialmente com fundos perdidos para pequenas empresas de base tecnológica (Lahorgue \& Cunha, 2003, p. 203).

3) Decisão de tipo de sociedade empresarial: levantada como importante no modelo norte-americano (Bagley \& Dauchy, 2003), esta decisão facilita a transferência futura de participação na empresa, que pode ocorrer, por exemplo, com venda de ações ou de toda a empresa. Esta decisão tem baixa importância no Brasil, pois iniciar a empresa como Sociedade Anônima não traz ganhos sensíveis.

4) Decisão quanto à proteção intelectual: nos EUA há maior incentivo para utilização de mecanismos de proteção intelectual (Holt, 1992, p. 172) dada a menor impunidade para infratores. Um exemplo de diferença no tratamento aos infratores entre EUA e Brasil é a indústria de software. Outra razão pelo baixo número de registros nacionais advém do alto custo associado (Barbieri, 1999, p. 56).

\section{CONSIDERAÇÕES FINAIS E CONTRIBUIÇÕES}

O modelo proposto neste estudo foi elaborado para apoiar a prática educacional pelos atuais e futuros empreendedores das principais decisões presentes no estágio de criação de um negócio e na análise de suas consequiências e incerteza envolvida. Apesar de desenvolvido para um simulador de jogos de empresas, o modelo conceitual é igualmente válido para qualquer atividade educacional em Empreendedorismo. Aqui é sugerido o uso em jogos de empresas pela efetividade deste método educacional em comparação a outros comumente utilizados (B. Keys \& Wolfe, 1990): os jogos de empresas facilitam a transposição de conceitos para as atividades empresariais pela ênfase em tomada de decisões.

Este estudo trouxe quatro contribuições para a literatura brasileira de empreendedorismo e de jogos de empresas:

a) Validade conceitual: destaca-se que o modelo proposto, diferentemente do TEG e do DEAL, declara o procedimento metodológico para a seleção das decisões - extensa pesquisa bibliográfica complementada por levantamento de campo junto a professores e pesquisadores em empreendedorismo. Nessa contribuição ainda se destaca a utilização do método de diagrama de 
influências na modelagem da inter-relação das decisões. Parte importante dessa contribuição é a publicação do modelo conceitual em meio acadêmico, dificilmente verificada na literatura.

b) Novas decisões: o modelo proposto inclui melhorias e amplia os simuladores publicados até o momento em meios acadêmicos - TEG e DEAL - quanto a número de decisões, apresentando oito novas decisões consideradas importantes no estágio de criação de um negócio, as quais foram destacadas na Tabela 4. Além destas, há ainda outras quatro, tratadas apenas parcialmente nos modelos anteriormente publicados: a decisão de preço (D02), que não inclui peças de reposição ou acessórios - como os cartuchos de tinta para impressoras, a vivência pelos participantes dos papéis dos líderes de desenvolvimento técnico (D13) e de mercado (D14) e a divisão da participação acionária (D11).

Tabela 4: Novas Decisões do Modelo Proposto

\begin{tabular}{|l|l|}
\hline D03 & Quanto investir em P\&D para cada um dos atributos do produto/serviço? \\
\hline D04 & Quanto investir em marketing do produto por canal de comunicação? \\
\hline D05 & Que canais de venda utilizar? \\
\hline D07 & Quanto produzir e quanto terceirizar (make or buy)? \\
\hline D08 & Realizar P\&D interno na empresa e/ou realizar parceria com instituição de ensino e pesquisa? \\
\hline D12 & De que forma é possível se desfazer do negócio em 5 anos? \\
\hline D19 & Qual propriedade intelectual registrar? \\
\hline D20 & Qual é o próximo produto a ser lançado após o estágio de criação de empresa? \\
\hline Fonte: elaborada pelos autores.
\end{tabular}

c) Ajuste ao contexto brasileiro: foram identificadas neste estudo as variáveis que distinguem o contexto empreendedor brasileiro. As principais distinções entre o empreendedorismo nos EUA e no Brasil estão relacionadas às seguintes decisões: oportunidade de negócio a perseguir (indústrias distintas); financiamento (capitalistas de risco privados versus Governo, além de diferentes taxas de juros); tipo de sociedade empresarial; investimentos em proteção intelectual.

d) Ciclo de vida das organizações [CVO]: o modelo proposto é o único, entre aqueles direcionados para empreendedorismo, que reconhece a variação das decisões prioritárias de acordo com o estágio evolutivo em que a organização se encontra. Para trazer contribuições mais relevantes neste sentido resta ainda expandir o presente modelo ao longo dos estágios evolutivos do CVO, especialmente para o estágio de crescimento.

Apesar de a aplicação do modelo não ser o foco deste estudo, cabe ressaltar que o foco poderia ser utilizado para diversos públicos no âmbito do Empreendedorismo. Como público-alvo podem ser citados alunos tanto da área de Administração e correlatas, quanto de áreas técnicas e tecnológicas, como a Engenharia ou a Biotecnologia. O mesmo também pode ser utilizado em diferentes níveis de formação: técnico, superior ou pós-graduação, sendo respeitada a complexidade, em termos de número de decisões e número de alternativas em cada decisão, de acordo com o perfil dos participantes. Há ainda a possibilidade de aplicá-lo fora de cursos regulares, em extensões ou cursos abertos, para diferentes públicos com representatividade populacional, como é o caso de pessoas de baixa renda e de idosos. É necessário, porém, a avaliação prévia do perfil dos participantes e do objetivo educacional para definir a complexidade das decisões a serem praticadas, o tempo de duração da atividade e o grau em que os conceitos de Administração devem ser passados, objetivando sempre o aproveitamento da atividade pelos participantes. 


\section{LIMITAÇÕES E PROPOSIÇÕES PARA NovOs Estudos}

O estudo limitou-se a modelar conceitualmente o primeiro estágio do ciclo de vida das organizações. Por um lado, ele pode ser ampliado para o estágio do crescimento, destacando as diferenças na gestão das empresas em ambos os estágios. Por outro, poderá ser estendido para o desenvolvimento do modelo matemático e realização de aplicações-teste.

Outra proposição seria realizar a modelagem de acordo com o público-alvo específico. A questão neste caso é a escolha entre um simulador mais genérico, que atende a diversos públicos, e um mais específico, para grupos com interesse semelhante. Um exemplo seria focalizá-lo em incubadoras de empresas, pois variáveis tecnológicas poderiam ser trazidas à tona. Outro grupo de interesse vislumbrado é o do empreendedorismo corporativo, que busca inovações no lançamento de novos produtos e serviços em corporações existentes, realçando diferenças quanto ao financiador do projeto, à estrutura de apoio e ao sistema de governança.

Artigo recebido em 15.10.2007. Aprovado em 27.08.2008.

\section{REFERÊNCIAS BIBLIOGRÁFICAS}

Andlinger, G. (1958). Business games - play one! Harvard Business Review, 36(2), 115-125.

Andreassi, T., \& Siqueira, E. (2005, agosto/setembro). Financiamento de novos negócios de base tecnológica no Brasil. Anais do Simpósio de Administração da Produção, Logística e Operações Internacionais, São Paulo, SP, Brasil, 8.

Araújo, M. H., Lago, R. M., Oliveira, L. C. A., Cabral, P. R. M., Cheng, L. C., \& Filion, L. J. (2005). O estímulo ao empreendedorismo nos cursos de química: formando químicos empreendedores. Química Nova, 28(Supl.), 18-25.

Bagley, C. E., \& Dauchy, C. E. (2003). The entrepreneur's guide to business law (2nd ed.). Mason, Ohio: Thomson.

Balestrin, A., \& Vargas, L. M. (2004). A dimensão estratégica das redes horizontais de PMEs: teorizações e evidências. Revista de Administração Contemporânea, 8(Edição Especial), 203-227.

Barbieri, J. C. (1999). Os inventores no Brasil: tipos e modalidades de incentivos. Revista de Administração de Empresas, 39(2), 54-63.

Bellman, R., Clark, C. E., Malcolm, D. G., Craft, C. J., \& Ricciardi, F. M. (1957). On the construction of a multi-stage, multi-person business game. Operations Research, 5(4), 469-503.

Bhidé, A. (1999). Bootstrap finance: the art of start-ups. In W. A. Sahlman, H. H. Stevenson, M. J. Roberts, \& A. Bhidé (Eds.). The entrepreneurial venture (2nd ed.). Boston: Harvard Business School Press.

Birch, D. L. (1987). Job creation in America: how our smallest companies put the most people to work. New York: Free Press.

Bosma, N., \& Harding, R. (2007). Global entrepreneurship: GEM 2006 summary results. Global Entrepreneurship Monitor. Recuperado em 14 junho, 2008, de http://www.gemconsortium.org/download.asp?fid=532 
Brouwer, M. T. (2002). Weber, Schumpeter and Knight on entrepreneurship and economic development. Journal of Evolutionary Economics, 12(1), 83-105.

Clemen, R. T., \& Reilly, T. (2001). Making hard decisions with decisiontools (2nd ed.). Belmont, CA: Duxbury.

Cohen, K. J., \& Rhenman, E. (1961). The role of management games in education and research. Management Science, 7(2), 131-166.

Conselho Nacional de Desenvolvimento Científico e Tecnológico. (2006). Plataforma Lattes. Recuperado em 12 julho, 2006, de http://lattes.cnpq.br

Coordenação de Aperfeiçoamento de Pessoal de Nível Superior. (2007). Resultados da avaliação 2007 (triênio 2004/2006): administração, ciências contábeis e turismo. Recuperado em 20 setembro, 2006, de http://conteudoweb.capes.gov.br/conteudoweb/AvaliacaoTrienalServlet?ano=2006

Crawford, M., \& Benedetto, A. (2003). New products management (7th ed.). New York: McGrawHill/Irwin.

Damodaran, A. (2003). Avaliação de investimentos: ferramentas e técnicas para a determinação do valor de qualquer ativo. São Paulo: Qualitymark.

Dutra, I. S. (2004, setembro). Ambiente empreendedor e mortalidade empresarial: estudo do perfil do empreendedor da micro e pequena empresa no norte do Paraná. Anais do Encontro Nacional da Associação Nacional de Pós-Graduação e Pesquisa em Administração, Curitiba, PR, Brasil, 28.

Goldschmidt, P. C. (1977). Simulação e jogo de empresas. Revista de Administração de Empresas, 17(3), 43-46.

Hanks, S. H., \& Chandler, G. N. (1995). Patterns of formalization in emerging business ventures. Proceedings of the Annual Babson College Entrepreneurship Resear Ch Conference: Frontiers of Entrepreneurship Research, Babson Park, MA, 15. Recuperado em 12 abril, 2009, de http://www.babson.edu/entrep/fer/papers95/hanks.htm

Harvard Business School. (2008). Arthur rock center for entrepreneurship. Business Plan Contest. Recuperado em 15 junho, 2008, de http://www.hbs.edu/news/releases/businessplan2008.html

Henry, C., Hill, F., \& Leitch, C. (2005). Entrepreneurship education and training: can entrepreneurship be taught? Part I. Education + Training, 47(2), 98-111.

Holt, D. H. (1992). Entrepreneurship: new venture creation. New Jersey: Prentice-Hall.

Judice, V. M. M., \& Baêta, A. M. C. (2005). Modelo empresarial, gestão da inovação e investimentos de venture capital em empresas de biotecnologia no Brasil. Revista de Administração Contemporânea, 9(1), 171-191.

Katz, J. (2003). Chair list. John Cook School of Business. Saint Louis University. Recuperado em 5 março, 2007, de http://www.slu.edu/x17963.xml

Katz, J., \& Boal, K. (2006). Entrepreneurship journal rankings. Recuperado em 22 fevereiro, 2007, de http://www.marketingtechie.com/articles/mtart20020307.pdf

Keys, B., \& Wolfe, J. (1990). The role of management games and simulations in education and research. Journal of Management, 16(2), 307-336.

Keys, J. B., \& Biggs, W. D. (1990). A review of business games. In J. W. Gentry (Ed.). Guide to business gaming and experiential learning (pp. 48-73). London, USA: Nichols/GP Publishing. 
Kirzner, I. M. (1979). Perception, opportunity, and profit: studies in the theory of entrepreneurship. Chicago, USA: University of Chicago Press.

Knight, F. H. (1921). Risk, uncertainty, and profit. Recuperado em 28 março, 2007, de http://www.econlib.org/library/Knight/knRUP.html

Lahorgue, M. A., \& Cunha, N. (2003). Introduction of innovations in the industrial structure of a developing region: the case of the Porto Alegre Technopole 'HomeBrokers' project. International Journal of Technology Management \& Sustainable Development, 2(3), 191-204.

Low, M. B., Venkataraman, S., \& Srivatsan, V. (1994). Developing an entrepreneurship game for teaching and research. Simulation \& Gaming, 25(3), 383-401.

MSI Management Simulations, Inc. (2006). Capstone business simulation student guide. [Manual]. Northfield, IL: USA. Recuperado em 14 Abril, 2009 de http://www.hamline.edu/gsm/current_and_new/syllabi/summer2006/GPA_8491_HOWARD_M PLS_200515.pdf

Murphy, P. J., Liao, J., \& Welsch, H. P. (2006). A conceptual history of entrepreneurial thought. Journal of Management History, 12(1), 12-35.

Rosas, A. R., \& Sauaia, A. C. A. (2006, setembro). Jogos de empresas na educação superior no Brasil: Perspectivas para 2010. Anais do Encontro Nacional da Associação Nacional de PósGraduação e Pesquisa em Administração, Salvador, BA, Brasil, 30.

Santos, S. A. (1983). A criação de empresas industriais: a figura do empreendedor e a influência da tecnologia no processo. Tese de doutorado, Universidade de São Paulo, São Paulo, SP, Brasil.

Sauaia, A. C. A. (2006). Lógica econômica, raciocínio estratégico e evolução organizacional: além das regras do jogo de empresas. Tese de livre-docência, Universidade de São Paulo, São Paulo, SP, Brasil.

Sauaia, A. C. A. (2007). Gestão da Estratégia: um guia prático [Manual do participante]. São Paulo: FEA/USP.

Schumpeter, J. A. (1934). The theory of economic development: an inquiry into profits, capital, credit, interest, and the business cycle. Cambridge, Mass: Harvard University Press.

Serviço Brasileiro de Apoio às Micro e Pequenas Empresas. (2004). Fatores condicionantes e taxa de mortalidade de empresas no Brasil. Recuperado em 5 janeiro, 2006, de http://www.sebraemg.com.br/arquivos/informativos/relatorio_pesquisa_mortalidade_minas.pdf

Serviço Brasileiro de Apoio às Micro e Pequenas Empresas. (2005). Boletim estatístico de micro e pequenas empresas. Recuperado em 1 junho, 2006, de http://www.pe.sebrae.com.br:8080/notitia/dowload/boletimestatistico.pdf

Shachter, R. D. (1986). Evaluating influence diagrams. Operations Research, 34(6), 871-882.

Silva, A. B., \& Pereira, A. A. (2004, setembro). Fatores de influência na gestão das empresas de pequeno e médio porte da grande Florianópolis/SC. Anais do Encontro Nacional da Associação Nacional de Pós-Graduação e Pesquisa em Administração, Curitiba, PR, Brasil, 28.

Souza, E. C. L., Souza, C. C. L., Assis, S. A. G., \& Zerbini, T. (2004, setembro). Métodos e técnicas de ensino e recursos didáticos para o ensino do empreendedorismo em IES brasileiras. Anais do Encontro Nacional da Associação Nacional de Pós-Graduação e Pesquisa em Administração, Curitiba, PR, Brasil, 28. 
Stevenson, H. H. (1999). A perspective on entrepreneurship. In W. A. Sahlman, H. H. Stevenson, M. J. Roberts, \& A. Bhidé (Eds.). The entrepreneurial venture (2nd ed.). Boston: Harvard Business School Press.

Strategic Excellence. (2005). The L'Oréal E-strat participant pre-reading manual. [Manual], França: Stratx.

Tanabe, M. (1973). Jogos de empresas. Dissertação de mestrado, Universidade de São Paulo, São Paulo, SP, Brasil.

Thavikulwat, P. (1995). Computer-assisted gaming for entrepreneurship education. Simulation \& Gaming, 26(3), 328-345.

Timmons, J. A., \& Spinelli, S. (2006). New venture creation: entrepreneurship for the 21st century (7th ed.). New York: McGraw-Hill/Irwin.

Vesper, K. H., \& Mcmullan, W. E. (1988). Entrepreneurship: today courses, tomorrow degrees? Entrepreneurship Theory and Practice, 13(1), 7-13. 